\title{
Astragalus Extract Mixture HT042 Increases Longitudinal Bone Growth Rate by Upregulating Circulatory IGF-1 in Rats
}

\author{
Donghun Lee, ${ }^{1}$ Sung Hyun Lee, ${ }^{2}$ Yoon Hee Lee, ${ }^{2}$ Jungbin Song, ${ }^{1}$ and Hocheol Kim ${ }^{1}$ \\ ${ }^{1}$ Department of Herbal Pharmacology, Kyung Hee University College of Korean Medicine, Seoul 02447, Republic of Korea \\ ${ }^{2}$ Korea Institute of Science and Technology for Eastern Medicine (KISTEM), NeuMed Inc., Seoul 02440, Republic of Korea \\ Correspondence should be addressed to Hocheol Kim; hckim@khu.ac.kr
}

Received 22 February 2017; Revised 1 May 2017; Accepted 22 May 2017; Published 20 June 2017

Academic Editor: I-Min Liu

Copyright (c) 2017 Donghun Lee et al. This is an open access article distributed under the Creative Commons Attribution License, which permits unrestricted use, distribution, and reproduction in any medium, provided the original work is properly cited.

\begin{abstract}
Astragalus extract mixture HT042 is a standardized ingredient of health functional food approved by Korean FDA with a claim of "height growth of children." HT042 stimulates bone growth rate and increases local IGF-1 expression in growth plate of rats which can be considered as direct stimulation of GH and its paracrine/autocrine actions. However, it remains unclear whether HT042 stimulates circulatory IGF-1 which also plays a major role to stimulate bone growth. To determine the effects on circulatory IGF-1, IGF-1 and IGFBP-3 expressions and phosphorylation of JAK2/STAT5 were evaluated in the liver after 10 days of HT042 administration. HT042 upregulated liver IGF-1 and IGFBP-3 mRNA expression, IGF-1 protein expression, and phosphorylation of JAK2/STAT5. HT042 also increased bone growth rate and proliferative zonal height in growth plate. In conclusion, HT042 stimulates bone growth rate via increment of proliferative rate by upregulation of liver IGF-1 and IGFBP-3 mRNA followed by IGF1 protein expression through phosphorylation of JAK2/STAT5, which can be regarded as normal functioning of GH-dependent endocrine pathway.
\end{abstract}

\section{Introduction}

Longitudinal bone growth is the result of chondrocyte proliferation and ensuing hypertrophy in growth plates, called endochondral ossification which is mainly controlled by a system of growth hormone- (GH-) insulin-like growth factor-1 (IGF-1) axis [1]. Mammalian growth plate consists of three principal zones: resting, proliferative, and hypertrophic zones. In resting zone, $\mathrm{GH}$ begins its actions by direct stimulation of resting stem-like chondrocytes to start proliferation. The following cell replication in proliferative zone and terminal differentiation and enlargement in hypertrophic zone are both primarily caused by circulatory IGF-1 $[2,3]$ and locally expressed IGF-1 [4].

Circulatory IGF-1 is biosynthesized in the liver as an endocrine hormone in the ternary form bound to IGF binding protein-3 (IGFBP-3) and acid labile subunit (ALS), while IGF-1 is also expressed by nonliver tissues including growth plate, where it works in a paracrine/autocrine fashion
[5]. For better understanding of the endocrine versus the paracrine/autocrine roles of IGF-1 in bone growth, previous studies have been used to examine the relative contribution to longitudinal bone growth. It has been widely reported that longitudinal growth is mainly mediated by paracrine/autocrine actions of IGF-1 based on the Yakar et al. study that liver IGF-1 deficient mice developed normally in spite a 75\% reduction in serum IGF-1 levels due to compensatory serum GH and nonhepatic IGF-1 [6,7]. But, years later, the same team revealed that circulatory IGF-1 is important for maintaining normal growth by the study that liver IGF-1 and ALS double knockout mice were much smaller because there was a decrease in not only IGF-1 production but also circulatory IGF-1 stability that originated from compensatory nonliver sources because of the absence of protective ALS protein [3]. This suggests that circulatory IGF-1 plays a major role in longitudinal bone growth rate.

Almost $80 \%$ of circulatory IGF-1 is produced by liver in humans and rodents. It is well established that circulatory 
IGF-1 levels are regulated posttranscriptionally mainly by GH at the postnatal period [8]. For production of circulatory IGF1 , actions of $\mathrm{GH}$ are started by its binding to $\mathrm{GH}$ receptor (GHR) on the surface of liver cells [9]. This causes dimerization of receptor and phosphorylation of GHR-related tyrosine kinase Janus kinase 2 (JAK2) [10]. Phosphorylated JAK2 phosphorylates signal transducers and activators of transcription 5 (STAT5) and phosphorylated STAT5 translocate to the nucleus and stimulates the IGF-1 transcription [11].

Astragalus extract mixture, HT042, consisting of the roots of Astragalus membranaceus and Phlomis umbrosa and the stem of Eleutherococcus senticosus, is a standardized ingredient of health functional foods approved by Korean FDA with a claim that "HT042 may help height growth of children" based on the evidence derived from randomized controlled trials. HT042 stimulates longitudinal bone growth rate in rats and increases the expressions of local IGF-1 in the proliferative and hypertrophic zones of the tibial growth plate which can be considered as direct stimulation of $\mathrm{GH}$ and its paracrine/autocrine actions [12-14]. However, it remains unclear whether HT042 stimulates circulatory IGF-1 which plays a major role to stimulate longitudinal bone growth.

To evaluate whether HT042 affects circulating IGF-1, we evaluated liver IGF-1 and IGFBP-3 mRNA expressions by quantitative real-time PCR and liver IGF-1 protein levels and the phosphorylation of JAK2/STAT5 by western blot in response to HT042 administration. We observed that HT042 increased bone growth rate and zonal height of growth plate of proximal tibia. Tetracycline was employed as a fluorescent reagent to identify anew formed bone by the growth plate.

\section{Methods}

2.1. Sample. Standardized HT042 was provided from NeuMed (Korea). Manufacturing process and quality management of HT042 were conducted in accordance with the methods registered in Korean FDA. Standardized HT042 contains shanzhiside methyl ester $0.15 \%$, eleutheroside E $0.36 \%$, and formononetin $0.008 \%$. For the quality verification, the quantitative analysis of HT042 was performed by high-performance liquid chromatography (HPLC) for measuring concentrations of marker compounds of $A$. membranaceus, E. senticosus, and P. umbrosa (formononetin, eleutheroside E, and shanzhiside methyl ester, resp.).

2.2. Animals. Female Sprague-Dawley rats with an age of 25 days were bought from Samtako (Korea). The present study was performed according the guidelines of the Institutional Animal Care and Use Committee, Korea Institute of Science and Technology for Eastern Medicine (KISTEM-IACUC2016-001). Rats were housed under constant temperature and humidity conditions with food and water ad libitum.

2.3. Treatment. After 7-day acclimatization, rats were assigned into 3 groups: vehicle, recombinant human $\mathrm{GH}$ (rhGH, Eutropin, LG, Korea) $200 \mu \mathrm{g} / \mathrm{kg}$, and HT042 $100 \mathrm{mg} /$ $\mathrm{kg}$. HT042 or distilled water vehicle was orally treated twice daily (8:00 am; 8:00 pm) and rhGH was subcutaneously treated once daily (8:00 am) for 10 days.
2.4. Real-Time Quantitative Polymerase Chain Reaction (PCR) Analysis. After sacrifice, livers were promptly removed, rinsed, and stored at $-80^{\circ} \mathrm{C}$. Total RNA from liver samples was extracted using QIAzol reagent (Qiagen, USA) and converted into cDNA with transcription kit (Applied Biosystems, USA) according to the instructions. Quantitative PCR was performed on a real-time PCR system (Applied Biosystems, USA) as follows: after $10 \mathrm{~m}$ at $95^{\circ} \mathrm{C}, 40$ cycles of $15 \mathrm{~s}$ at $95^{\circ} \mathrm{C}$ and $60 \mathrm{~s}$ at $60^{\circ} \mathrm{C}$. Primers were designed and synthesized by Bioneer (Korea): insulin-like growth factor-1 (GenBank Accession Number M15481), forward 5-GCTATGGCTCCAGCATTCG-3 and reverse 5-TCCGGAAGCAACACTCATCC-3; insulin-like growth factor-binding protein-3 (GenBank Accession Number NM_012588), forward 5-GGAAAGACGACGTGCATTG-3 and reverse 5-GCGTATTTGAGCTCCACGTT-3; glyceraldehyde-3phosphate dehydrogenase (GAPDH, GenBank Accession Number NM_017008), forward 5-TGGCCTCCAAGGAGTAAGAAAC- 3 and reverse 5-CAGCAACTGAGGGCCTCTCT-3. Conditions were as follows: $10 \mathrm{~min}$ at $95^{\circ} \mathrm{C}$ and 40 cycles of $15 \mathrm{~s}$ at $95^{\circ} \mathrm{C}$ and $60 \mathrm{~s}$ at $60^{\circ} \mathrm{C}$. Relative quantifications was performed using the delta-delta $\mathrm{Ct}$ method with normalization to GAPDH expression.

2.5. Growth Plate Height. Cresyl violet (CV, Sigma-Aldrich, USA) was used to stain chondrocytes for measuring height of growth plate. Overall growth plate height and zonal height were measured by using ImageJ software (NIH, USA) at 3 locations as previously described [15].

2.6. Measuring Longitudinal Bone Growth Rate. Tetracycline hydrochloride (20 mg/kg, i.p., Sigma-Aldrich) was injected $72 \mathrm{~h}$ before sacrifice as previously described [15]. Dissected tibias were fixed with $4 \%$ paraformaldehyde, decalcified in $50 \mathrm{mM}$ EDTA solution (Sigma-Aldrich) and dehydrated in $30 \%$ sucrose solutions overnight. Dehydrated tibias were sectioned in the sagittal plane with $40 \mu \mathrm{m}$ thickness on a cryostat (CM3050S, Leica Microsystems, Germany). Daily longitudinal growth rate was estimated by dividing the distance between tetracycline label and chondroosseous junction into three. Tetracycline label was examined with a fluorescent microscope (BX50, Olympus, Japan) and the distance was measured with ImageJ by three different researchers in a blind manner. Rats for measuring longitudinal bone growth rate were used separately because tetracycline injection can affect other parameters.

2.7. Western Blotting. Protein from rat liver samples was extracted using the PRO-PREP ${ }^{\mathrm{TM}}$ (iNtRON Biotechnology, Korea) in accordance with the manufacturer's instructions. Total protein concentrations were quantified by Bradford reagent (Bio-Rad, USA). Total protein $50 \mu \mathrm{g}$ was denatured in load buffer and separated using SDS-PAGE on Bolt ${ }^{\mathrm{TM}}$ 4-12\% Bis-Tris gel (Invitrogen, USA). After electrophoresis, separated proteins were electrotransferred onto PVDF membranes (Merck Millipore, Germany). The membrane was blocked with $5 \%$ skim milk for $1 \mathrm{~h}$ at room temperature. After the blocking, membranes were incubated overnight at 
$4^{\circ} \mathrm{C}$ with the respective primary antibodies: mouse monoclonal anti- $\beta$-actin antibody (Sigma-Aldrich, USA; diluted 1:20000), mouse monoclonal anti-IGF-1 antibody (Abcam; diluted $1: 2500$ ), rabbit polyclonal anti-STAT5 antibody (Cell Signaling Technology; diluted $1: 1000)$, rabbit polyclonal antiphospho-STAT5 antibody (Tyr694, Cell Signaling Technology; diluted 1:1000), rabbit polyclonal anti-JAK2 antibody (Cell Signaling Technology; diluted $1: 1000$ ), and rabbit polyclonal anti-phospho-JAK2 antibody (Tyr1008, Cell Signaling Technology; diluted 1:1000). After washing, the membrane was incubated with horseradish peroxidase-conjugated secondary anti-mouse IgG antibody (Sigma-Aldrich, USA; diluted 1:3000) or horseradish peroxidase-conjugated secondary anti-rabbit IgG antibody (Sigma-Aldrich, USA; diluted $1: 3000)$. The membranes were developed by using ECL prime detection reagent (GE Healthcare, UK). Protein expression was detected with an Amersham Imager 600 (GE Healthcare, UK).

2.8. Enzyme-Linked Immunosorbent Assay (ELISA). For the quantitative analysis of the serum IGF-1 concentration, a sandwich assay for IGF-1 was carried out in duplicate in a 96-well ELISA kit according to the manufacturer's protocol (RMEE25R, BioVendor, Czech Republic).

2.9. Statistical Analysis. Statistical analysis was performed with GraphPad Prism 6 software (USA). One-way analysis of variance with post hoc Newman-Keuls test was used for multiple comparisons. Statistical significance was set at $p<$ 0.05 . All values were presented as mean $\pm \mathrm{SD}$.

\section{Results}

3.1. Quantitative Analysis of HT042. Quantitative analysis of HT042 by HPLC was performed to determine the concentrations of the marker compounds for quality assurance. The result showed that the concentrations of formononetin, eleutheroside E, and shanzhiside methyl ester were in the range of $64.0-96.0 \mu \mathrm{g} / \mathrm{g}, 2.88-4.32 \mathrm{mg} / \mathrm{g}$, and $1.20-1.80 \mathrm{mg} / \mathrm{g}$, respectively (Figure 1).

\subsection{Effect on IGF-1 and IGFBP-3 $m R N A$ Expression in Liver.} Previously, we showed that HT042 administration increased IGF-1 expression on the local growth plate of normal rats [12-14]. To evaluate whether HT042 affects circulating IGF1 , quantitative real-time PCR was conducted to measure liver IGF-1 and IGFBP-3 mRNA expressions because serum IGF-1 is synthesized primarily in the liver in a GH-dependent manner [16]. Oral administration of HT042 $100 \mathrm{mg} / \mathrm{kg}$ significantly increased mRNA expression of IGF-1 and IGFBP-3 in the liver exhibiting 1.6- and 1.4-fold values compared to the control group, respectively, although the increment was smaller compared to rhGH (Figure 2).

\subsection{Effect on IGF-1 Protein Expression and JAK2/STAT5} Phosphorylation in the Liver. To determine whether growthstimulating effect of HT0 42 was mediated by the phosphorylation of JAK2 and STAT5 which cause IGF-1 production, we performed western blotting. As expected, IGF-1 protein was predominantly expressed in HT042 group compared to control group. Phosphorylations of JAK2 and STAT5 in the liver were upregulated by HT042 (Figure 3).

3.4. Effect on Circulating IGF-1 Level. To examine whether HT042 increases circulating IGF-1 level, we measured the serum IGF-1 concentration by ELISA. Figure 4 shows the numerical value of serum IGF-1 concentration of each group. Serum IGF-1 concentration in the control group was $518.4 \pm$ $72.2 \mathrm{ng} / \mathrm{mL}$. Administration of rhGH and HT042 for 10 days significantly increased the serum IGF-1 exhibiting $882.1 \pm$ $192.5 \mathrm{ng} / \mathrm{mL}$ and $625.8 \pm 117.9 \mathrm{ng} / \mathrm{mL}$ compared to the control group, respectively.

3.5. Effect on Longitudinal Bone Growth Rate. To assess the effect of HT042 on bone growth rate, tetracycline was employed as a fluorescent reagent to mark freshly formed bone beneath growth plate. The double arrows indicate the distance of bone growth in proximal tibia for $72 \mathrm{~h}$ (Figure 5). Figure 6 shows the numerical value of bone growth rate of each group. Bone growth rate in the control group was $378.5 \pm 24.6 \mu \mathrm{m} /$ day. Administration of rhGH and HT042 significantly increased the bone growth rate exhibiting $406.9 \pm$ $24.1 \mu \mathrm{m} /$ day and $393.2 \pm 18.8 \mu \mathrm{m} /$ day compared to the control group, respectively.

3.6. Effect on the Growth Plate Height. Height of proximal tibial growth plate was measured with CV staining (Figure 7). Overall growth plate height was $350.3 \pm 19.6 \mu \mathrm{m}$ in control group. Administration of rhGH and HT042 significantly increased height of growth plate exhibiting $365.4 \pm$ $17.3 \mu \mathrm{m}$ and $365.6 \pm 23.9 \mu \mathrm{m}$ compared to the control group, respectively. Height of proliferative zone, particularly, was significantly increased in HT042 group compared to control (Table 1).

\section{Discussion}

Oral administration of Astragalus extract mixture HT042 at a dose of $100 \mathrm{mg} / \mathrm{kg}$ for 10 days upregulated liver IGF$1 \mathrm{mRNA}$ and protein expression and increased circulating IGF-1 level via the phosphorylation of JAK2/STAT5. HT042 also significantly increased height of proliferative zone and longitudinal bone growth rate and increased the local IGF-1 and BMP-2 expressions in growth plate.

HT042 showed significant upregulation of liver IGF-1 and IGFBP-3 mRNA expression compared to control. Liver is the main source of circulatory IGF-1 and IGFBP-3 in a manner dependent on GH [17]. In a mammalian, almost $80 \%$ of circulatory IGF-1 is carried by IGFBP-3 to prolong the half-life of IGF-1 and transport IGF-1 to its receptor [18] and diminishing of IGFBP-3 weakens its IGF-1 protective ability. For these reasons, serum levels of IGF-1 and IGFBP-3 are thought to be excellent biochemical parameters reflecting $\mathrm{GH}$ level which is widely fluctuating over time $[19,20]$. The positive impact of the HT042 on IGF-1 or IGFBP-3 mRNA expression is in accordance with previous studies reporting the increasing effect of formononetin and $\beta$-glucan of 


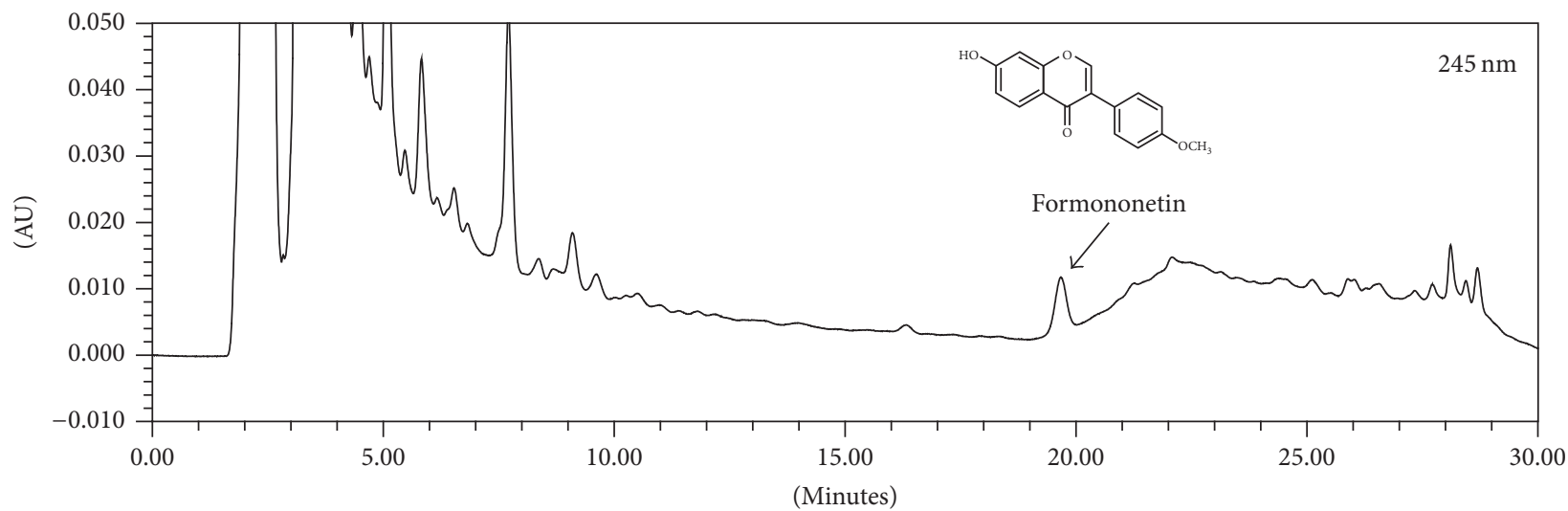

(a)

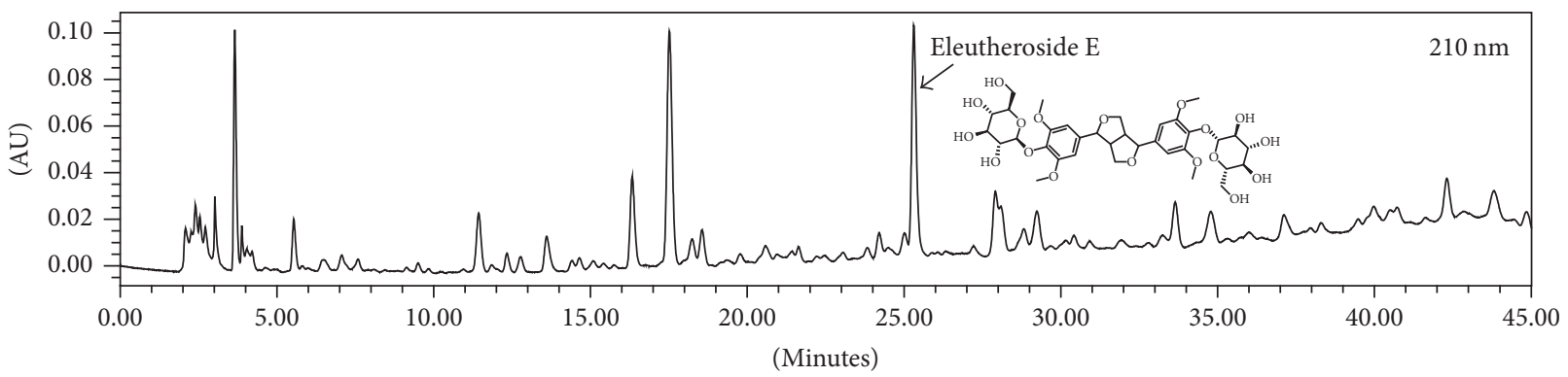

(b)

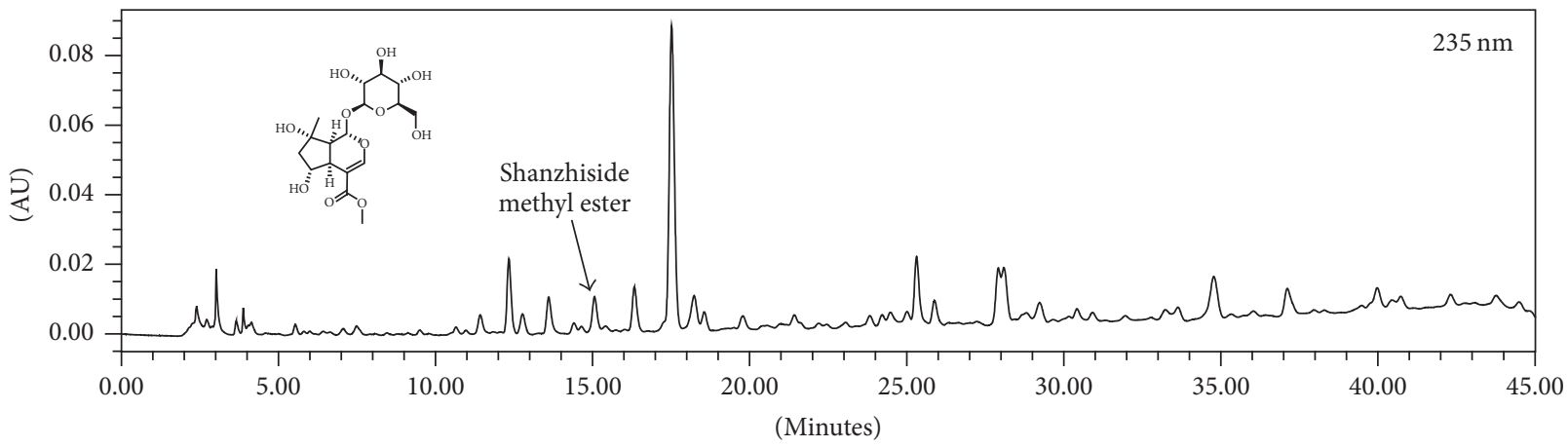

(c)

FIGURE 1: HPLC chromatograms of (a) formononetin, (b) eleutheroside E, and (c) shanzhiside methyl ester, the marker compounds of $A$. membranaceus, E. senticosus, and P. umbrosa, respectively, in the HT042.

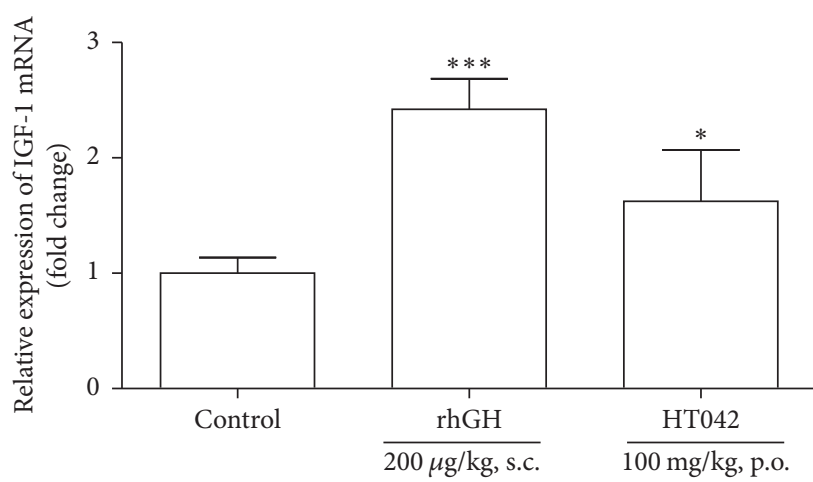

(a)

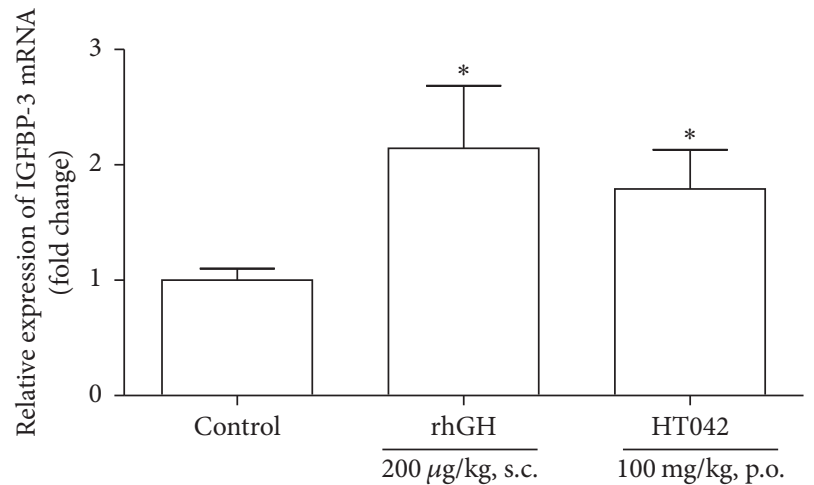

(b)

FIGURE 2: The relative expression of IGF-1 and IGFBP-3 mRNA in the liver measured by quantitative real-time PCR. Relative transcriptional levels of (a) IGF-1 and (b) IGFBP-3 were analyzed by applying to GAPDH internal control; ${ }^{*} p<0.05$ and ${ }^{* * *} p<0.001$ versus control. 


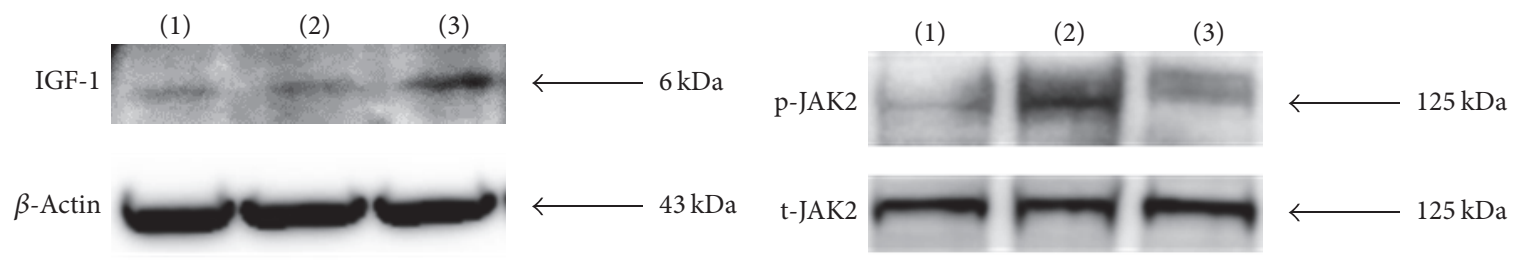

(a)

(b)

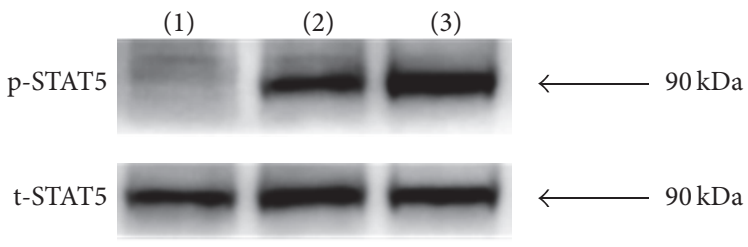

(c)

FIGURE 3: The protein levels of IGF-1 and JAK2/STAT5 in the liver measured by western blot. (a) IGF-1, (b) phosphor- (p-)JAK2/total- (tJJAK2, and (c) p-STAT5/t-STAT5; (1) control group, (2) rhGH $200 \mu \mathrm{g} / \mathrm{kg}$ (s.c.) treated group, and (3) HT042 $100 \mathrm{mg} / \mathrm{kg}$ (p.o.) treated groups.

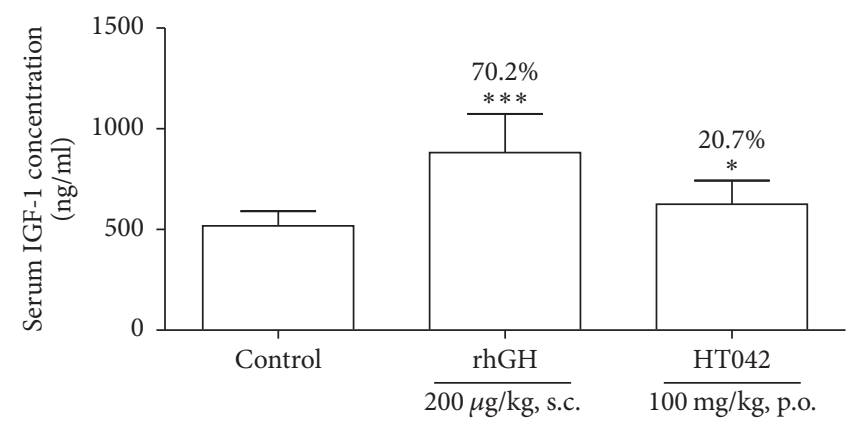

FIgURE 4: The serum concentration of IGF-1 measured by ELISA; ${ }^{*} p<0.05$ and ${ }^{* * *} p<0.001$ versus control.

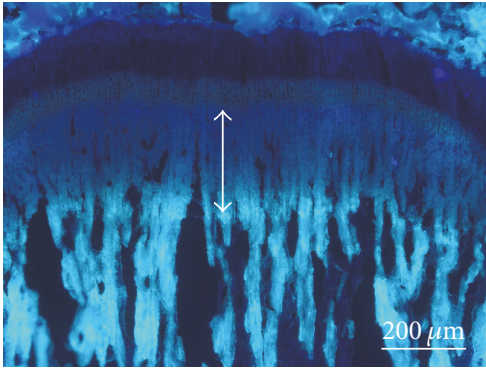

(a)

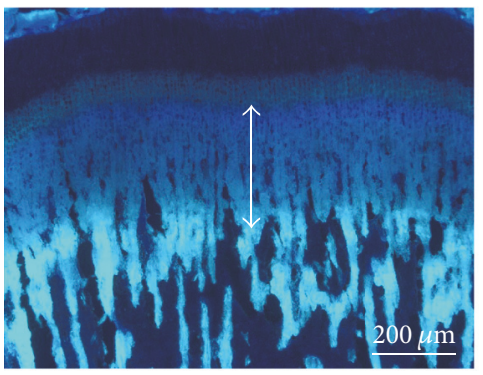

(b)

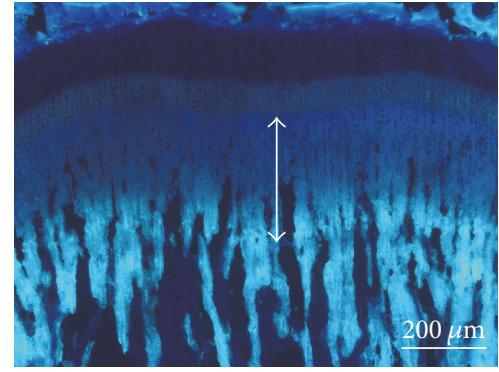

(c)

FIGURE 5: Typical fluorescent photography of proximal growth plate of tibia. The double arrows indicate the distance of bone growth in proximal tibia for $72 \mathrm{~h}$. (a) Control; (b) rhGH $200 \mu \mathrm{g} / \mathrm{kg}$ (s.c.); (c) HT042 $100 \mathrm{mg} / \mathrm{kg}$ (p.o.). Scale bar, $200 \mu \mathrm{m}$.

A. membranaceus, A. senticosus polysaccharide, and $P$. umbrosa extracts on serum IGF-1 or IGFBP-3 concentration $[15,21,22]$. In the previous study, we found that HT042 does not alter bone growth rate of spontaneous dwarf rat which can not produce intact GH mRNA, suggesting HT042 may stimulate $\mathrm{GH}$ secretion rather than act like $\mathrm{GH}[12,23]$. Taken together, the results suggest that the effects of HT042 on bone growth rate might be attributable to the increment of circulatory IGF-1 and IGFBP-3 by the stimulation of GH.

HT042 increased circulating IGF-1 level and liver IGF1 protein expression with the increment of phosphorylation of JAK2/STAT5 protein. It is well established that circulatory IGF-1 is mainly produced in the liver and regulated posttranscriptionally by $\mathrm{GH}$ at the postnatal period. $\mathrm{GH}$ signaling is mediated by protein phosphorylation cascades, thereby activating nuclear proteins and transcription factors [24]. Binding of $\mathrm{GH}$ to its receptor leads to activation of JAK2, which in turn phosphorylates STAT5. Then, STAT5 translocates to the nucleus, binds to certain DNA sequence, and regulates transcription [25]. Among the signaling cascades induced by GH, JAK2/STAT5 signaling cascade plays a major role in $\mathrm{GH}$ regulation of gene transcription in liver 
TABLE 1: Height of growth plate in each group.

\begin{tabular}{lccc}
\hline$\mu \mathrm{m}$ & Control & rhGH 200 $\mu \mathrm{g} / \mathrm{kg}$ (s.c.) & HT042 100 mg/kg (p.o.) \\
\hline Overall height & $350.3 \pm 19.6$ & $365.4 \pm 17.3^{*}$ & $365.6 \pm 23.9^{*}$ \\
Resting zone & $22.0 \pm 5.3$ & $21.4 \pm 5.2$ & $20.2 \pm 3.8$ \\
Proliferative zone & $119.9 \pm 11.5$ & $127.3 \pm 15.7$ & $133.6 \pm 11.2^{* *}$ \\
Hypertrophic zone & $198.5 \pm 12.7$ & $203.3 \pm 17.6$ & $205.3 \pm 20.8$ \\
\hline
\end{tabular}

${ }^{*} p<0.05$ and $^{* *} p<0.01$ versus control.

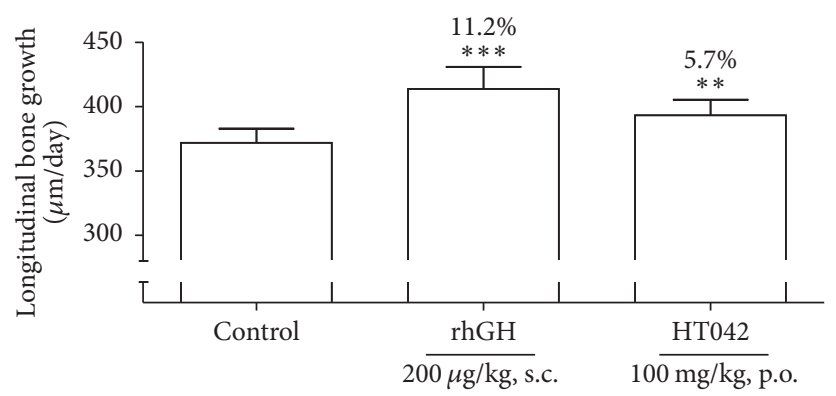

FIGURE 6: Effects of HT042 on bone growth rate in proximal growth plate of tibia; ${ }^{* *} p<0.01$ and ${ }^{* * *} p<0.001$ versus control.

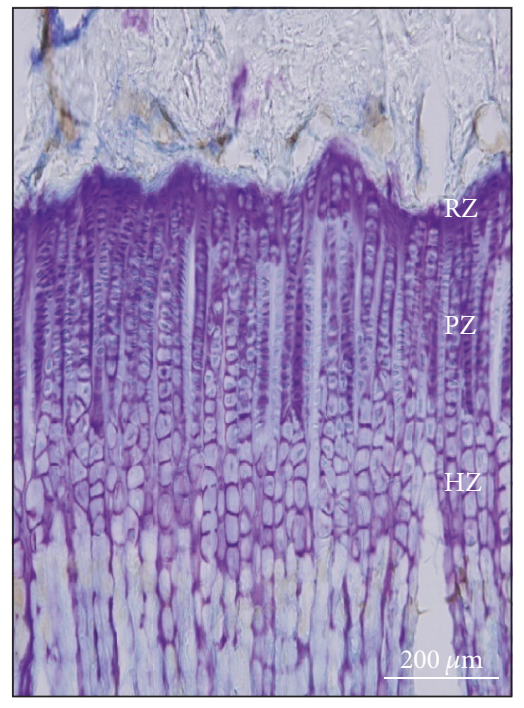

(a)

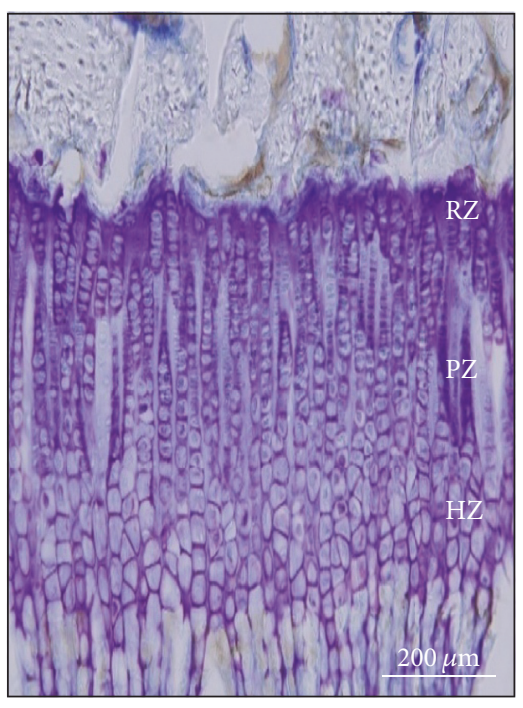

(b)

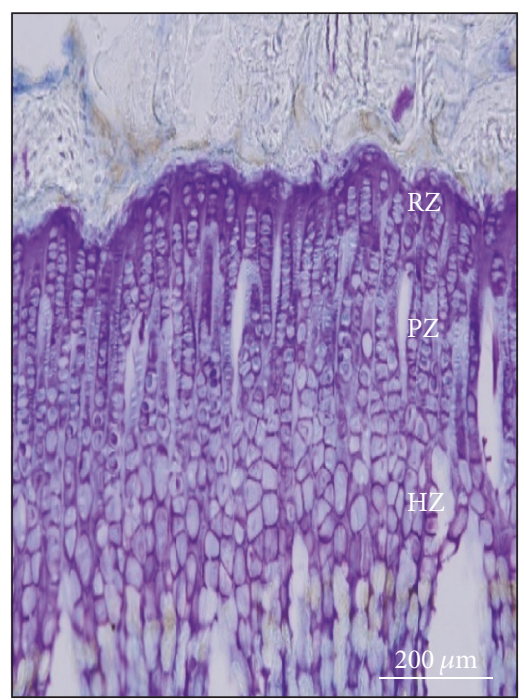

(c)

FIGURE 7: Photography of cresyl violet-stained chondrocytes in proximal growth plate of tibia; (a) control, (b) rhGH $200 \mu \mathrm{g} / \mathrm{kg}$ (s.c.), and (c) HT042 $100 \mathrm{mg} / \mathrm{kg}$ (p.o.). Scale bar, $200 \mu \mathrm{m}$.

[26]. Moreover, this pathway has been reported to be in charge of GH-induced liver IGF-1 expression [27]. Our results showing that HT042 increases IGF-1 levels in both serum and liver with the phosphorylation of JAK2/STAT5 suggest that the growth-stimulating effect of HT042 is mediated by the increment of circulating IGF-1 through the JAK2/STAT5 signal cascade.

When liver IGF-1 production is increased, circulating level of ternary complexes consisting of IGF-1, IGFBP-3, and ALS is increased in serum and then isolated IGF-1 binds to IGF-1 receptors of local growth plates and stimulates proliferation of chondrocytes which cause increment of the height of growth plates [3]. To assess this, we analyzed the zonal height of proximal growth plate in rat tibia. HT042 significantly increased overall growth plate height by $4.4 \%$ particularly proliferative zonal height by $11.4 \%$ compared to control. Among three characteristic areas of growth plate, fast division at proliferative zone and ensuing expansion at hypertrophic zone result in bone growth rate and height of growth plate. Particularly, the greatest contribution to bone growth rate is the rate of clonal proliferation which results in increase in proliferative zone height [5]. Previous researchers have detected close correlations between proliferative zonal height and bone growth rate regardless of other factors [28-30]. The 
result suggests that HT042 increases proliferation rate of the chondrocytes in growth plate by upregulation of liver IGF-1 and IGFBP-3 expressions.

We already reported that HT042 at doses of $100 \mathrm{mg} / \mathrm{kg}$ for 4 consecutive days increased the bone growth rate measured by tetracycline in the proximal tibial growth plate. This method is hard to evaluate the efficacy accurately because of the excessive individual difference of rats and researchers. In the present study, rats with exactly the same days of age were used because the bone growth rate of rats varies excessively depending on the days of age. The distances were blind-read by three different researchers to avoid the distinction among individuals. Administration periods were extended to 10 consecutive days from 32-day-old to 41-day-old rats because rats reach sexual maturity at approximately 50 days of age and in the adolescent period 10 rat days are converted into 1 human year [31]. Oral administration of HT042 at a dose of $100 \mathrm{mg} / \mathrm{kg}$ for 10 days showed the significant increase of the longitudinal bone growth rate compared to the control group under well controlled condition in accordance with previous result suggesting that HT042 increases longitudinal bone growth rate.

\section{Conclusion}

Astragalus extract mixture HT042 stimulates bone growth rate via upregulation of liver IGF-1 and IGFBP-3 mRNA followed by IGF-1 protein levels in serum and liver through the phosphorylation of JAK2/STAT5, which can be considered as normal functioning of $\mathrm{GH}$-dependent endocrine pathway.

\section{Conflicts of Interest}

The authors declare that they have no conflicts of interest.

\section{References}

[1] O. Nilsson, R. Marino, F. De Luca, M. Phillip, and J. Baron, "Endocrine regulation of the growth plate," Hormone Research, vol. 64, no. 4, pp. 157-165, 2005.

[2] M. Reinecke, A. C. Schmid, B. Heyberger-Meyer, E. B. Hunziker, and J. Zapf, "Effect of growth hormone and insulin-like growth factor I (IGF-I) on the expression of IGF-I messenger ribonucleic acid and peptide in rat tibial growth plate and articular chondrocytes in vivo," Endocrinology, vol. 141, no. 8, pp. 28472853,2000 .

[3] S. Yakar, C. J. Rosen, W. G. Beamer et al., "Circulating levels of IGF-1 directly regulate bone growth and density," Journal of Clinical Investigation, vol. 110, no. 6, pp. 771-781, 2002.

[4] C. Ohlsson, S. Mohan, K. Sjögren et al., "The role of liverderived insulin-like growth factor-I," Endocrine Reviews, vol. 30, no. 5, pp. 494-535, 2009.

[5] B. C. J. Van Der Eerden, M. Karperien, and J. M. Wit, "Systemic and Local Regulation of the Growth Plate," Endocrine Reviews, vol. 24, no. 6, pp. 782-801, 2003.

[6] K. Sjögren, J. Liu, K. Blad et al., "Liver-derived insulin-like growth factor I (IGF-I) is the principal source of IGF-I in blood but is not required for postnatal body growth in mice," Proceedings of the National Academy of Sciences of the United States of America, vol. 96, no. 12, pp. 7088-7092, 1999.
[7] S. Yakar, J.-L. Liu, B. Stannard et al., "Normal growth and development in the absence of hepatic insulin-like growth factor I," Proceedings of the National Academy of Sciences of the United States of America, vol. 96, no. 13, pp. 7324-7329, 1999.

[8] L. J. Hall, Y. Kajimoto, D. Bichell et al., "Functional analysis of the rat insulin-like growth factor I gene and identification of an IGF-I gene promoter," DNA and Cell Biology, vol. 11, no. 4, pp. 301-313, 1992.

[9] A. J. Brooks and M. J. Waters, "The growth hormone receptor: Mechanism of activation and clinical implications," Nature Reviews Endocrinology, vol. 6, no. 9, pp. 515-525, 2010.

[10] T. Zhu, E. L. K. Goh, R. Graichen, L. Ling, and P. E. Lobie, "Signal transduction via the growth hormone receptor," Cellular Signalling, vol. 13, no. 9, pp. 599-616, 2001.

[11] J. Herrington, L. S. Smit, J. Schwartz, and C. Carter-Su, "The role of STAT proteins in growth hormone signaling," Oncogene, vol. 19, no. 21, pp. 2585-2597, 2000.

[12] J. Y. Kim, M. Song, D. Lee et al., "Effect of HT042, herbal formula, on longitudinal bone growth in spontaneous dwarf rats," Molecules, vol. 18, no. 11, pp. 13271-13282, 2013.

[13] M.-Y. Kim, J. Y. Kim, D. Lim et al., "Skeletal growth and IGF levels in rats after HT042 treatment," Phytotherapy Research, vol. 26, no. 12, pp. 1771-1778, 2012.

[14] M.-Y. Kim, Y. Park, N. R. Pandit et al., "The herbal formula HT042 induces longitudinal bone growth in adolescent female rats," Journal of Medicinal Food, vol. 13, no. 6, pp. 1376-1384, 2010.

[15] D. Lee, Y.-S. Kim, J. Song et al., "Effects of phlomis umbrosa root on longitudinal bone growth rate in adolescent female rats," Molecules, vol. 21, no. 4, article 461, 2016.

[16] S. A. Kaplan and P. Cohen, "Review: the somatomedin hypothesis 2007: 50 years later," Journal of Clinical Endocrinology and Metabolism, vol. 92, no. 12, pp. 4529-4535, 2007.

[17] W. H. Daughaday, K. Hall, M. S. Raben, W. D. Salmon Jr., J. L. Van den Brand, and J. J. Van Wyk, "Somatomedin: proposed designation for sulphation factor," Nature, vol. 235, no. 5333, article 107, 1972.

[18] E. F. Costalonga, S. R. Antonini, G. Guerra Jr., B. B. Mendonca, I. J. P. Arnhold, and A. A. L. Jorge, "The -202 A allele of insulinlike growth factor binding protein-3 (IGFBP3) promoter polymorphism is associated with higher IGFBP-3 serum levels and better growth response to growth hormone treatment in patients with severe growth hormone deficiency," Journal of Clinical Endocrinology and Metabolism, vol. 94, no. 2, pp. 588595, 2009.

[19] R. G. Rosenfeld, "Is growth hormone deficiency a viable diagnosis?" Journal of Clinical Endocrinology and Metabolism, vol. 82, no. 2, pp. 349-351, 1997.

[20] D. C. M. Van der Kaay, A. E. J. Hendriks, W. A. Ester et al., "Genetic and epigenetic variability in the gene for IGFBP-3 (IGFBP3): correlation with serum IGFBP-3 levels and growth in short children born small for gestational age," Growth Hormone and IGF Research, vol. 19, no. 3, pp. 198-205, 2009.

[21] X. F. Mao, X. S. Piao, C. H. Lai, D. F. Li, J. J. Xing, and B. L. Shi, "Effects of $\beta$-glucan obtained from the Chinese herb Astragalus membranaceus and lipopolysaccharide challenge on performance, immunological, adrenal, and somatotropic responses of weanling pigs," Journal of Animal Science, vol. 83, no. 12, pp. 2775-2782, 2005.

[22] J. Han, L. Bian, X. Liu, F. Zhang, Y. Zhang, and N. Yu, "Effects of Acanthopanax senticosus polysaccharide supplementation on 
growth performance, immunity, blood parameters and expression of pro-inflammatory cytokines genes in challenged weaned piglets," Asian-Australasian Journal of Animal Sciences, vol. 27, no. 7, pp. 1035-1043, 2014.

[23] T. Takeuchi, H. Suzuki, S. Sakurai, H. Nogami, S. Okuma, and H. Ishikawa, "Molecular mechanism of growth hormone (Gh) deficiency in the spontaneous dwarf rat: detection of abnormal splicing of gh messenger ribonucleic acid by the polymerase chain reaction," Endocrinology, vol. 126, no. 1, pp. 31-38, 1990.

[24] Y. H. Joung, E. J. Lim, P. Darvin et al., "MSM Enhances GH Signaling via the Jak2/STAT5b Pathway in Osteoblast-Like Cells and Osteoblast Differentiation through the Activation of STAT5b in MSCs," PLoS ONE, vol. 7, no. 10, Article ID e47477, 2012.

[25] D. le Roith, C. Bondy, S. Yakar, J. L. Liu, and A. Butler, “The somatomedin hypothesis: 2001," Endocrine Reviews, vol. 22, no. 1, pp. 53-74, 2001.

[26] E. F. Gevers, M. J. Hannah, M. J. Waters, and I. C. A. F. Robinson, "Regulation of rapid signal transducer and activator of transcription-5 phosphorylation in the resting cells of the growth plate and in the liver by growth hormone and feeding," Endocrinology, vol. 150, no. 8, pp. 3627-3636, 2009.

[27] J. Woelfle, D. J. Chia, and P. Rotwein, "Mechanisms of growth hormone $(\mathrm{GH})$ action: Identification of conserved Stat 5 binding sites that mediate $\mathrm{GH}$-induced insulin-like growth factor-I gene activation," Journal of Biological Chemistry, vol. 278, no. 51, pp. 51261-51266, 2003.

[28] F. De Luca, K. M. Barnes, J. A. Uyeda et al., "Regulation of growth plate chondrogenesis by bone morphogenetic protein2," Endocrinology, vol. 142, no. 1, pp. 430-436, 2001.

[29] J. L. Kuhn, J. H. DeLacey, and E. E. Leenellett, "Relationship between bone growth rate and hypertrophic chondrocyte volume in New Zealand white rabbits of varying ages," Journal of Orthopaedic Research, vol. 14, no. 5, pp. 706-711, 1996.

[30] C. J. Xian, G. S. Howarth, J. C. Cool, and B. K. Foster, "Effects of acute 5-fluorouracil chemotherapy and insulin-like growth factor-I pretreatment on growth plate cartilage and metaphyseal bone in rats," Bone, vol. 35, no. 3, pp. 739-749, 2004.

[31] R. Quinn, “Comparing rat's to human's age: how old is my rat in people years?” Nutrition, vol. 21, no. 6, pp. 775-777, 2005. 


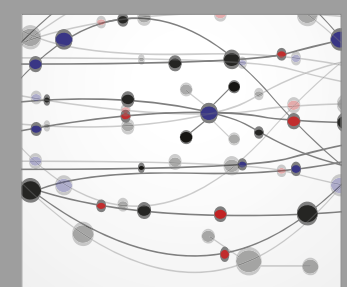

The Scientific World Journal
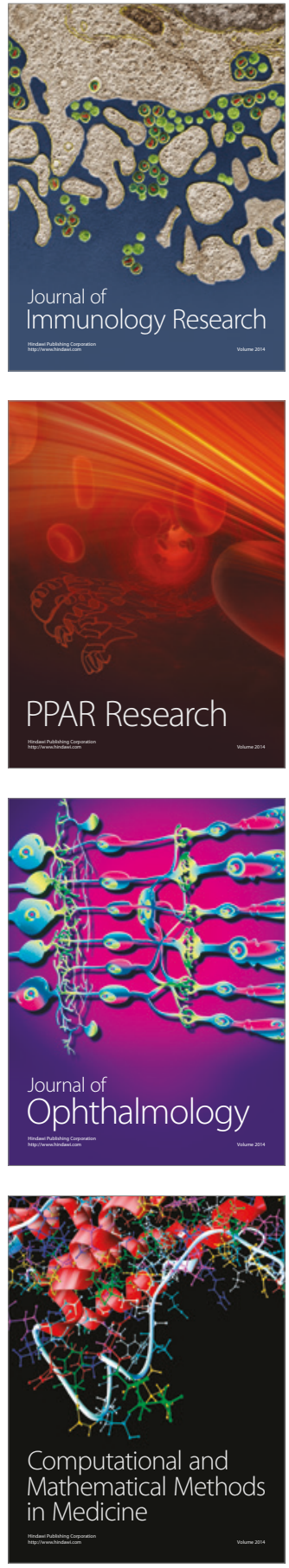

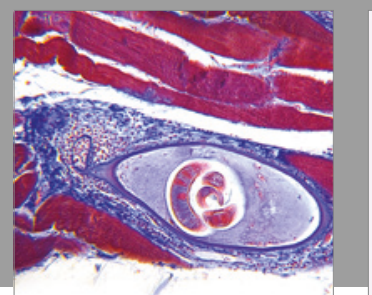

Gastroenterology Research and Practice
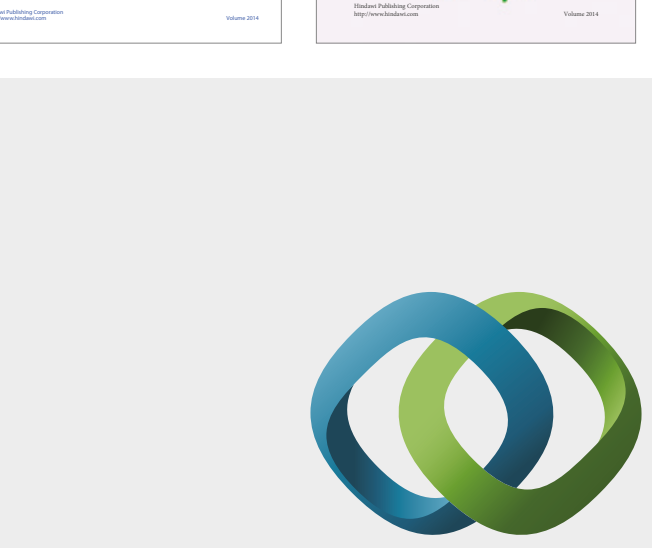

\section{Hindawi}

Submit your manuscripts at

https://www.hindawi.com
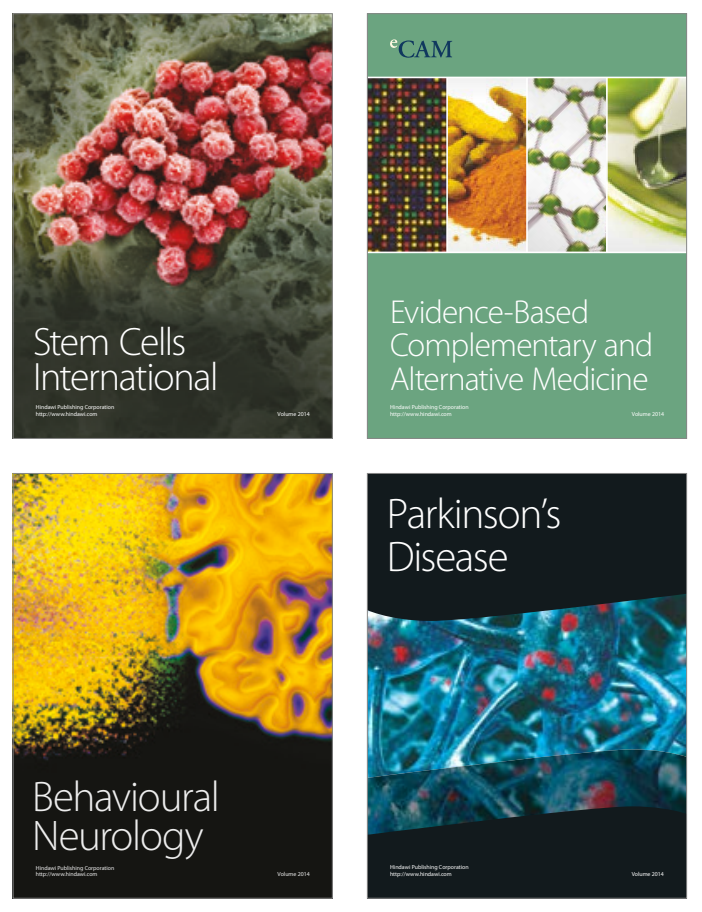
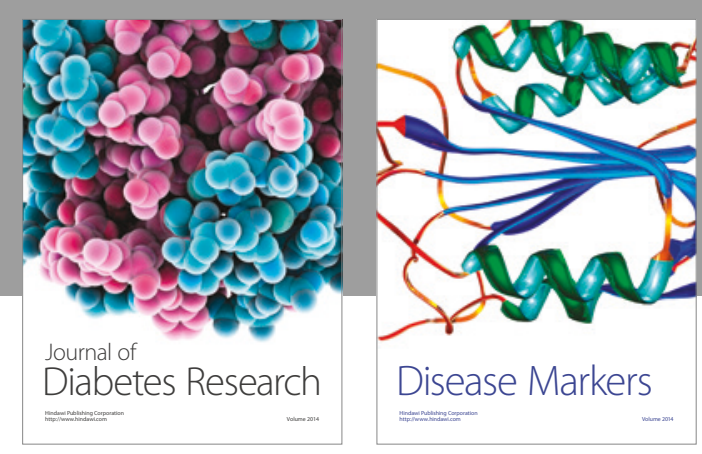

Disease Markers
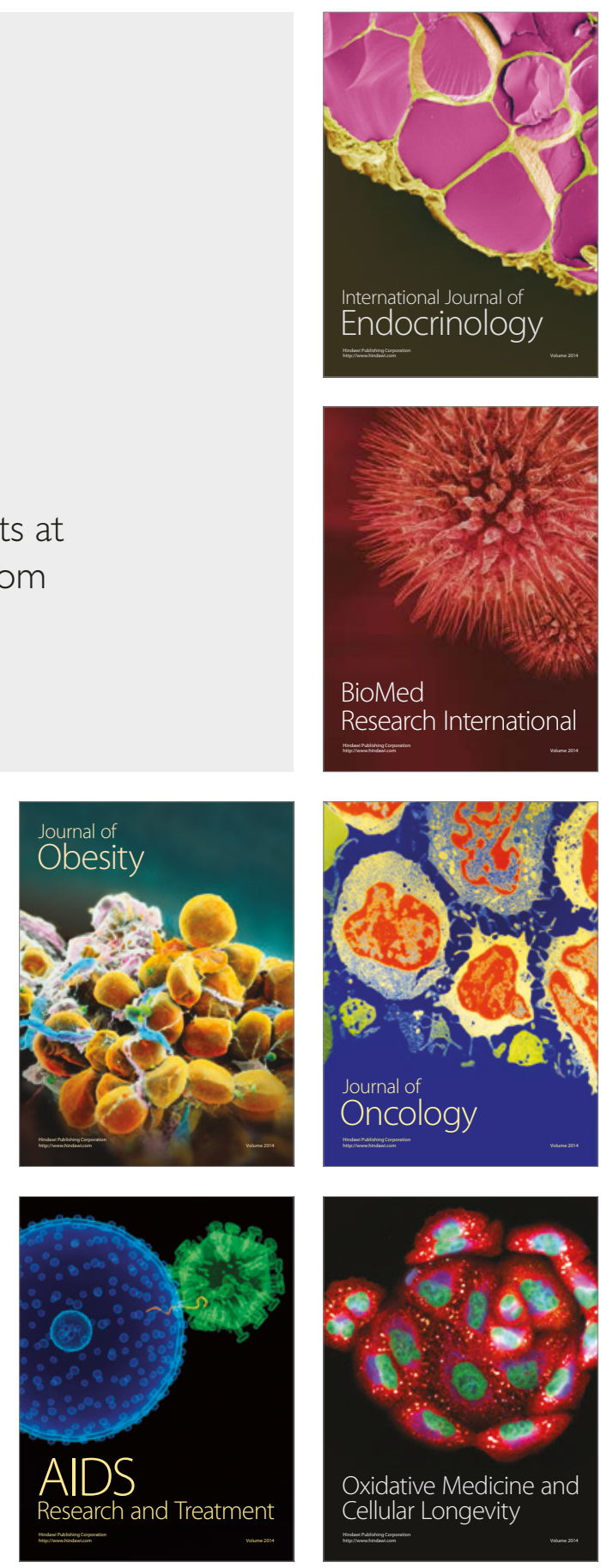